\title{
Development of QGIS Plugin to Monitor the Health Condition of a Lake
}

\author{
Shibu K, S. Ayoob
}

\begin{abstract}
Monitoring the quality of surface water is an important step towards sustainability of water resources. Quantum Geographic Information System(QGIS) is an opensource desktop application which is used for editing and analysing geospatial data. This study aims to develop a QGIS plugin named Lake Ecosystem Tool to monitor the health condition of a lake in terms of water quality index, trophic state index, hazard quotient, aerial water spread and volumetric changeand the same can be used as a planning tool for the sustainable management of existing water bodies.

Keywords: Health condition, Lake, Lake Ecosystem Tool, plugin, Quantum Geographic Information System.
\end{abstract}

\section{I.INTRODUCTION}

\section{W} ater is valued as one of the most valued resource for the survival of all living things. Hence preserving and if possible rejuvenating theexisting water environment is very much essential for life sustenance. Of late, the decline in water quality due to infusion of multitudinous pollutants into the natural water bodies is an issue of global concern.Monitoring health condition of lakes is thus anessential step in making appropriate decisions in the right directionfor improving the existing water quality. The need of the hour is quality monitoring and restoration of existing natural water systems [17].

Freshwater makes up only 2.5percentage of all the water available on this planet, out of which less than 1 percentage is directly available for human consumption. It is estimated that one sixth of the global populaceare living in areas where they don't have access to safe drinking water as a result of unsustainable water consumption, population explosion, industrialisation and climate change[16]. Moreover, the quality of the available water resources is also questionable due to overwhelming pollution. This calls for the adoption of efficient conservation measures for protecting the existing freshwater bodies.

Nowadays Geographical Information System (GIS) and Remote Sensing (RS)applications work hand in hand to survey large water spread areas,to compute water quality by sensing parameters namely $\mathrm{pH}$, chlorophyllconcentration, turbidityand salinity,and isconsidered

Manuscript received on April 24, 2021.

Revised Manuscript received on May 04, 2021.

Manuscript published on June 30, 2021.

* Corresponding Author

Shibu K*, Associate Professor, Department of Civil Engineering, College of Engineering, Trivandrum, Thiruvananthapuram (Kerala), India. Email: shibukrishnanp@gmail.com

Dr. S. Ayoob, Pro-Vice Chancellor, APJ Abdul Kalam Technological University, Thiruvananthapuram (Kerala), India. Email: ayoobtkm@gmail.com

(C) The Authors. Published by Blue Eyes Intelligence Engineering and Sciences Publication (BEIESP). This is an open access article under the CC BY-NC-ND license (http://creativecommons.org/licenses/by-nc-nd/4.0/) as one of the most powerful tool to solve complex research problems in theconservation and management of natural habitats. With recent advances in space technologies, multispectral satellite images provide satisfactory spectral resolution which can be used to determine the landuse landcover changeswith less error[14].

QGIS (QuantumGeographical Information System) is an open-source desktop GIS application which supports data formats for both tabular and spatial information[2].QGIS can read both raster and vector files and the software can georeference images as well[1].

The QGIS core is developed using toolkit and $\mathrm{C}++$ and Plugins written in $\mathrm{C}++$ or Python enhances the capabilities of QGIS that helps to add extra features to theexisting GIS software. Independent developers has extended the core functionality of GIS using python plugins as well[4].

Qt Creator is anintegrated software development environmentthat supports designer tools for developing Qt GUI (Graphical User Interphase)which is part of the SDK (Software Development Kit)[3]. Qt Creator includes a code editor and integrates Qt designer for designing and building graphical user interfaces (GUIs) from Qt widgets[5].In this study Qt Creator is used as a tool to create the framework of plugin which is used to monitor the health condition of a lake.

In order tomonitor the health condition of a lake in terms of different parameters, a common platform can be provided in the form of a QGIS plugin. The objective of this paper is to develop a plugin in QGIS namedLake Ecosystem Toolto monitor the health condition of a lake. It includes selected parameters related to water quality,water spread area, and volume of the lake.

Tool namely Ecosystem Health Index (EHI) was developedby Xuato assess the water quality ofa series of Italian lakesona scale ranging from 0 to 100 where 0 denotes the worst water quality and 100 the best water quality[20].Carlson developed an index namely Trophic State Index (TSI) to indicate the eutrophication condition of lakes in a scale ranging from 0 to 100 and the same was calculated using parameters namelysecchidepth, nitrogen content, phosphorus concentration andchlorophyll-a. [6].

Swamee and Tyagi expressed water quality with the help of an aggregate index which consisted of subindices. The same was doneto reduce the problems of rigidity,eclipsing and ambiguity with respect to the number of water quality variables required to be aggregated in a given index[15]

Peterson, carried out a study ondetermining the primary productivity of an aquatic environment and used the 14C-C02 method to describe the carbon flow in planktonic ecosystems [18].

Published By:

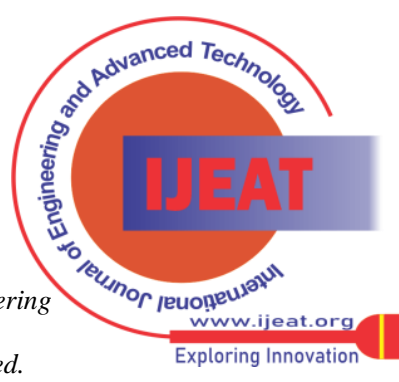


Arias-Gonza'lezet al.,used extensive ecological dataof Chinchorro Bank Biosphere Reserve to assess the rich biodiversity in coral reefs applying GIS and RS tools and predicted the same in terms of coral reef fish diversity index and habitat classification [8].

Carpenter et al., detailed on the lake primary productivity and demonstrated that the top to bottom control of primary production by nonliving componentsand a trophic cascade involving predation offish[9].Dodson et al., discussed about the relationship in lake communities between the rate at which solar energy is converted to organic substances andthe number of species present in that communityand concludedthat the same strongly dependent onwater spread area of the lake [10].French developed a simple procedureto determine theHierarchial Richness Index which could be applied at any level of top to bottom ecological heirarchial system[11].Theresearch carried out by Goldman detailed on the role ofprimary productivity, nutrients, and transparency in cultural eutrophication[12].Lawhead discussed the creation of plugins using Python programming in QGIS[5].

\section{II.METHODOLOGY}

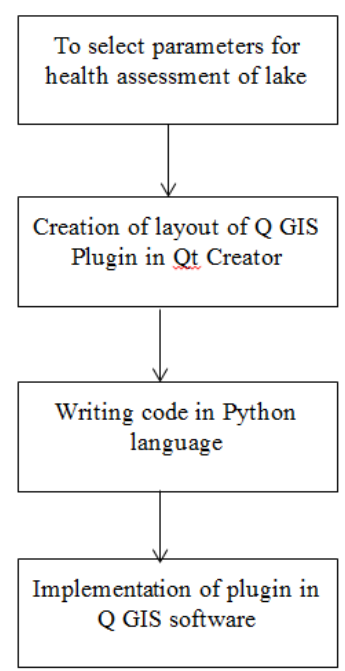

Fig. 1.Flow chart representing the methodology forcreating QGIS plugin

The flow chart representing the methodology for creating QGIS plugin is shown in Fig.1.Different parameters selected in this study forthe creation of QGIS plugin to determine the health condition of a lake areeutrophication in terms of Trophic State Index (TSI), water quality parameters in terms of Water Quality Index (WQI), heavy metal contamination in terms of Hazard Quotient (HQ), areal change in the lake water spread and the volumetric change of the lake.The different indices used in this study are discussed as follows.

HQ is expressed as the ratio of exposure contaminant concentration and the reference contaminant concentration and the same is used to determine the health risk. Values of HQ less than or equal to 1 indicates that ill effects areleast expected. If the value of $\mathrm{HQ}$ is greater than 1 , it does not mean that adverse effects will occur, but the same warrants a thorough analysis on the sampling locationswhere the concentration of chemicals has exceeded.

WQIderived from physical,chemical and biological parameters are expressed in terms of a single value and the same represents the overall water quality of the water body with respect to space and time. The said index simplifies a complex data set that is easily understandable by the public and sustainable conservation measures can be adopted by the policy makers as well [19].

National Sanitation Foundation Water Quality Index (NSFWQI) is commonly used for assessing water quality and the same has served as the basis for several other water quality indices that was developed later.The one developed by Swamee and Tyagiis commonly used to determinethe water quality in Southern part of India and the same is mathematically expressed as (1).

$$
I=\left(1-N+\sum_{i=1}^{N} S_{i}^{-1 / k}\right)^{-k}
$$

Where,

$$
\begin{aligned}
& \mathrm{N}=\text { Number of parameters chosen } \\
& \mathrm{S}=\text { Subindex value for } \mathrm{i}^{\text {th }} \text { water quality variable } \\
& \mathrm{k}=0.40
\end{aligned}
$$

The value of WQIdeveloped by Swamee and Tyagi ranges from 0 to 1 and the description for each division is given in table 1.

Table- 1: Range of Water Quality Index developed by Swamee and Tyagi

\begin{tabular}{|c|r|}
\hline WQI range & Qualitative descriptor of WQI \\
\hline $0-0.25$ & Poor water quality \\
\hline $0.26-0.5$ & Fair water quality \\
\hline $0.51-0.7$ & Medium or average water quality \\
\hline $0.71-0.9$ & Good water quality \\
\hline $0.91-1.0$ & Excellent water quality \\
\hline
\end{tabular}

Limiting nutrients namely nitrogen content and phosphorus concentration, along with water transparency and chlorophyll-a concentration is used for calculatingTSI[13],[7].Carlson's TSI is commonly used to determine the trophic condition of water bodies and the same is defined as the total weight of organic content at the time of measurement. The mathematical expression developed by Carlson is given as (2) [6].

$$
\mathrm{TSI}=0.25\left(\mathrm{TSI}_{\mathrm{SD}}+\mathrm{TSI}_{\mathrm{Chl}-\mathrm{a}}+\mathrm{TSI}_{\mathrm{TP}}+\mathrm{TSI}_{\mathrm{TN}}\right)
$$

Where $\quad \mathrm{TSI}_{\mathrm{SD}}=60.0-(14.41) * \ln (\mathrm{SD})$

$$
\mathrm{TSI}_{\mathrm{TP}}=(14.42) * \ln (\mathrm{TP})+4.15
$$

$$
\mathrm{TSI}_{\mathrm{TN}}=54.45+(14.43) * \ln (\mathrm{TN})
$$

Published By:

Blue Eyes Intelligence Engineering and Sciences Publication

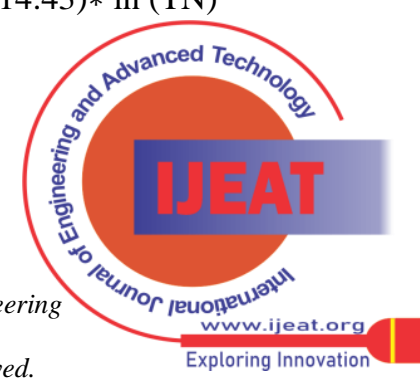




$$
\mathrm{TSI}_{\text {Chl-a }}=30.6+(9.81) * \ln (\mathrm{Chl}-
$$

a)

Where $\mathrm{SD}=$ Secchi Depth $(\mathrm{m}), \mathrm{TP}=$ Total Phosphorous $(\mu \mathrm{g} / \mathrm{L}), \mathrm{TN}=$ Total Nitrogen $(\mu \mathrm{g} / \mathrm{L})$ andChl-a $=$ Chlorophyll $(\mu \mathrm{g} / \mathrm{L})$. A lake is classified based on the TSI value and the descriptor words for thecorresponding trophic classesare given in table 2 [6].

Table-2: Classification of lakes based on TSI

\begin{tabular}{|c|c|}
\hline TSI & $\begin{array}{c}\text { Lake } \\
\text { Classification }\end{array}$ \\
\hline$<40$ & Oligotrophic \\
\hline 40-50 & Mesotrophic \\
\hline $51-70$ & Eutrophic \\
\hline$>70$ & Hypereutrophic \\
\hline
\end{tabular}

\section{III.RESULTS \& DISCUSSIONS}

The creation of plugin is carried out using the plugin builder plugin, which is accompanied with QGIS software. By installing the specific plugin, it leads the way to create a new plugin according to one's needs. The required inputs namely class name, plugin name, etc. should be given properly and the description for the new plugin is also given. Module name is also given to save the plugin. The details of author and the way they appear in the menu bar are shown in Fig. 2 and the plugin builder output is shown in Fig.3 respectively.

\begin{tabular}{|c|c|c|c|}
\hline \multicolumn{3}{|c|}{ QGIS Plugin Builder - Version 2.16.0 } & $?$ \\
\hline \multicolumn{4}{|c|}{ QGIS Plugin Builder } \\
\hline \multirow{9}{*}{$\begin{array}{r}\text { Class name } \\
\text { Plugin name } \\
\text { Description } \\
\text { Module name } \\
\text { Version number } \\
\text { Minimum QGIS version } \\
\text { Author/Company } \\
\text { Email address }\end{array}$} & Lake Ecosystem Tool & & \\
\hline & Lake Ecosystem Tool & & \\
\hline & To evaluate the health status of & & \\
\hline & lake_ecosystem_tool & & \\
\hline & 0.1 & & \\
\hline & 2.0 & & \\
\hline & Prashobh & & \\
\hline & prashobh94@gmail.com| & & \\
\hline & <Previous & Next > & Cancel \\
\hline
\end{tabular}

Fig. 2.Plugin creation using plugin builder tool in QGIS

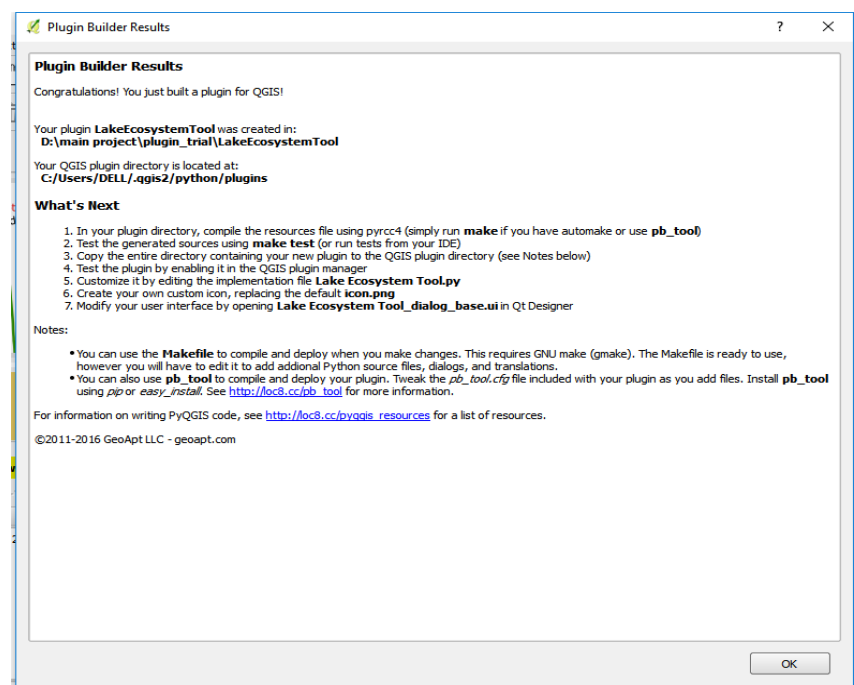

Fig. 3.Plugin builder output

After successful creation of plugin, the saved plugin should be called into the QGIS software. For this purpose, OSGeo4W(binary distribution of a broad set of open source geospatial software for Windows environment) shell is attached to QGIS software, which act as a binding of Python language to QGIS software. By opening, OSGeo4W shell, a window which is shown in Fig.4 is displayedwhichwill provide a space to give commands to get necessary outputs. Here, 'make' command is used to call the saved plugin into the QGISenvironment.

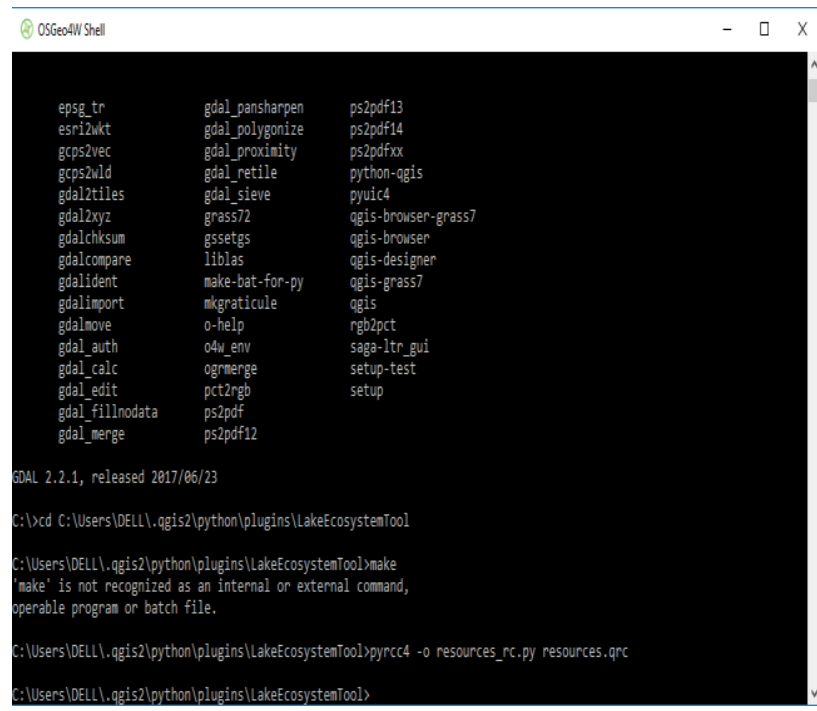

Fig. 4.Calling of plugin to the QGIS environment

After successful calling, the QGIS software can be opened to see whether the plugin is successfully created or not. The successfully created plugin here is saved as an experimental plugin named "Lake Ecosystem Tool" and the same is shown in Fig.5. Detailed description are also shown inFig.5 including the location of saved plugin in the system. Manual uninstalling and reinstalling of plugin can be done in QGIS, without using the code language.

Published By:

Blue Eyes Intelligence Engineering and Sciences Publication

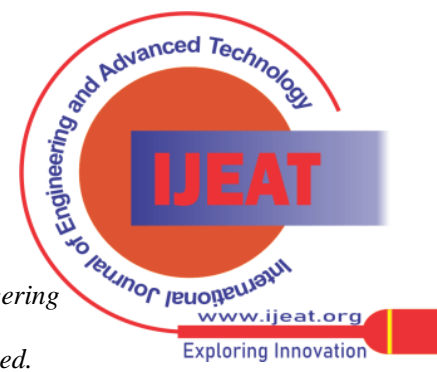




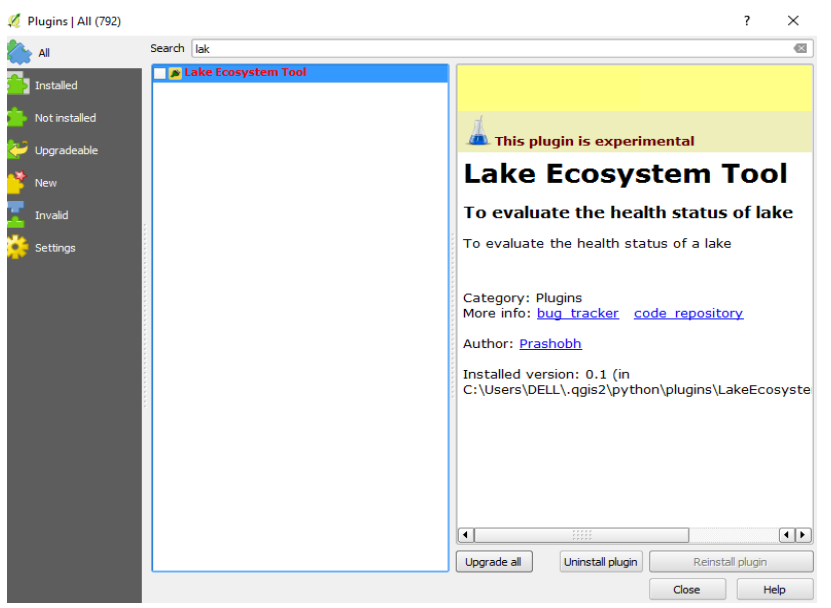

Fig. 5.Addition of QGIS plugin to the QGIS environment

The next stepwas to create the user interface of the plugin using the binding software, QtCreator and the same is shown in Fig.6.Qt Creator organisesits source code in projects and the researcher can configure QtCreator for compiling and editing one's code.

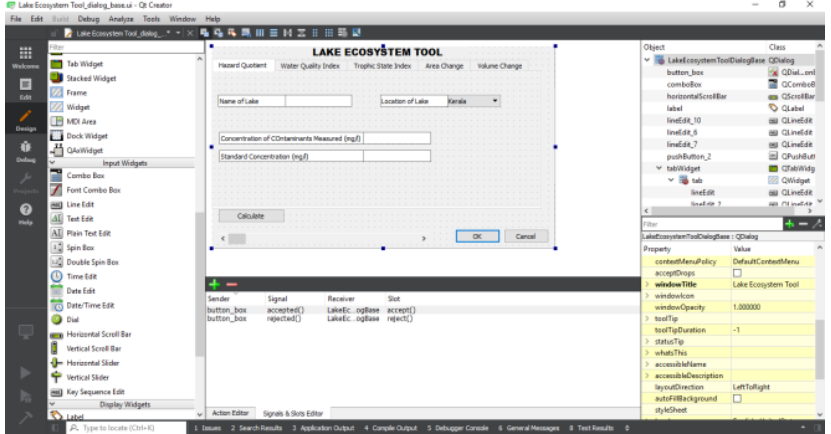

Fig. 6.Creation of user interface of plugin using QtCreator

The layout of the Lake Ecosystem Tool developed to calculate different indices such as HQ, WQI, and TSI are shown in Fig.7, Fig.8, and Fig.9 respectively. The same also provide the tabs for computingthe areal change and volume change of the lake. Provision for providing the name and location of lake is also given. Parameters can be selected from the scroll menu and the respective one can be given as input with proper units.Indices namelyHQ, WQI, and TSIcan be calculated using the relevantequationsand the same can be selected from the scroll menu.

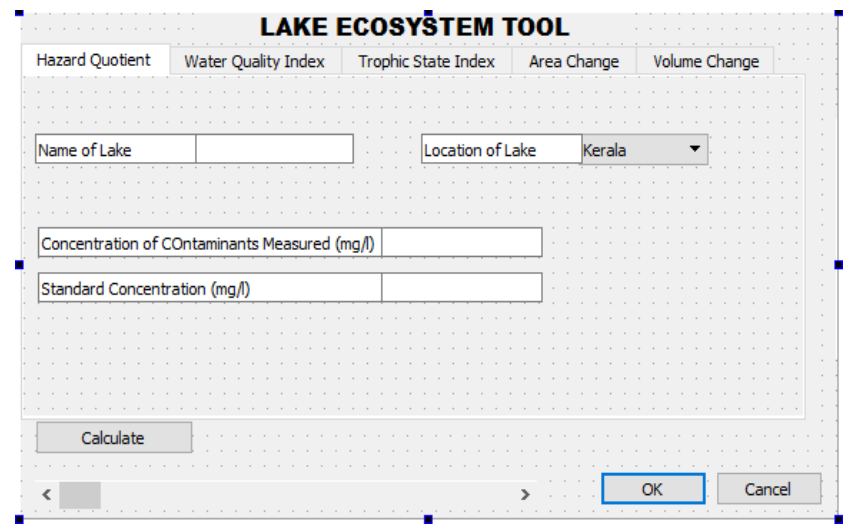

Fig. 7.Layout of plugin : Hazard Quotient tab

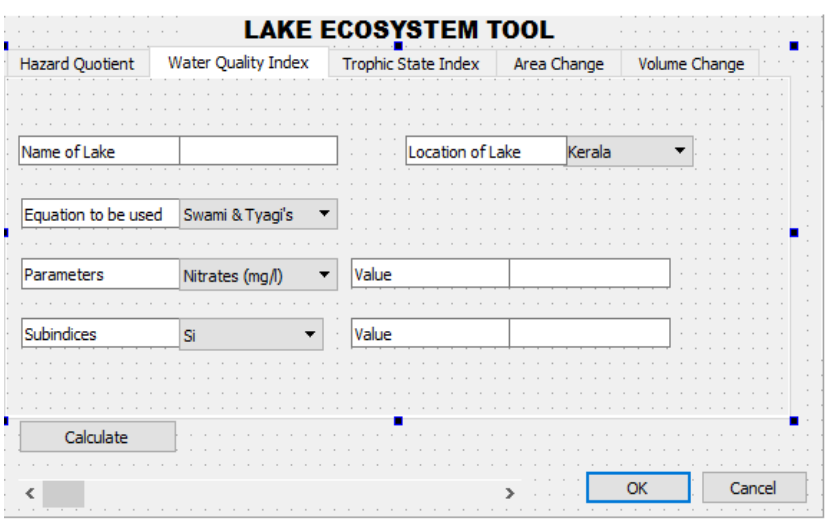

Fig. 8.Layout of plugin : Water Quality Index tab

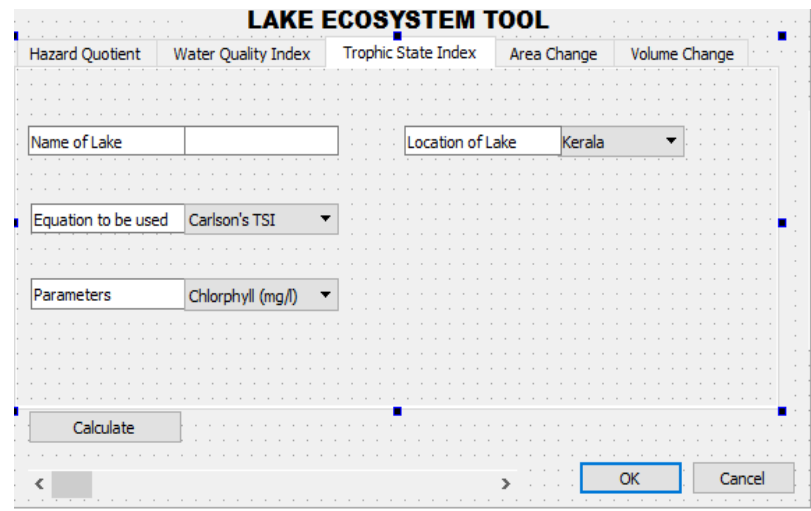

Fig. 9.Layout of plugin :Trophic State Index tab

Thereafter the Python code was edited within this software to provide the logic to the given layout. After successful edition of python language, the same provides the logical outputs expected as per one's requirement.Fig.10 shows thepython binding in QtCreator to provide the logic in the preferred manner.

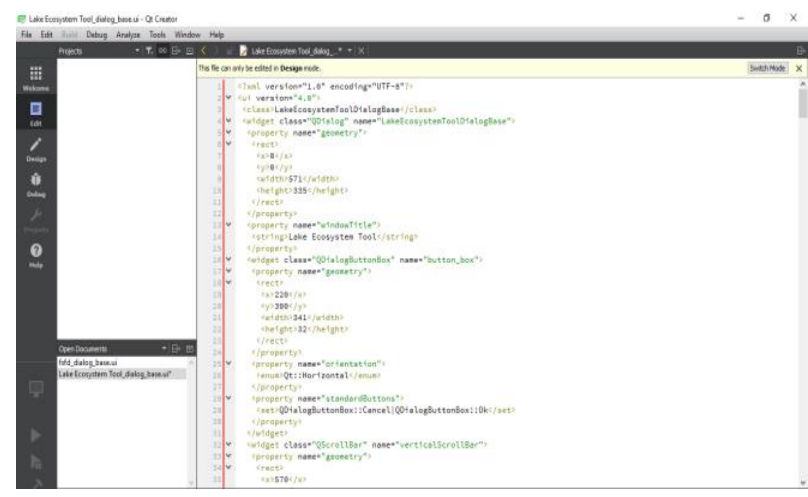

Fig. 10.Python code to bind the created plugin for the preferred logic

\section{IV.CONCLUSION}

Lake Ecosystem Tool developed in this studycould be useda simple valuable tool for assessing the health condition of lakesand the same can also be used for comparing the health status of a series of lakes.

Published By:

Blue Eyes Intelligence Engineering and Sciences Publication

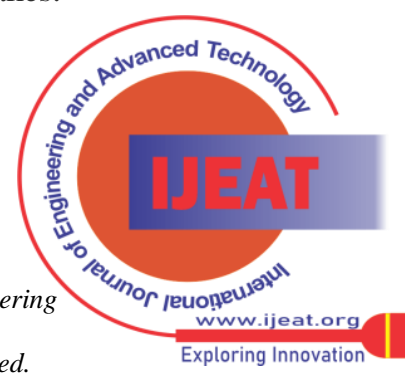




\section{ACKNOWLEDGMENT}

The authors thank Sri Prashobh, Post Graduate Scholar, Department of Civil Engineering, College of Engineering, Trivandrum for the support rendered in creating the Plugin using plugin builder tool in QGIS.

\section{REFERENCES}

1. Anders Nielsen ,Karsten Bolding, Fenjuan Hu , Dennis Trolle(2017) "An open source QGIS-based workflow for model application and experimentation with aquatic ecosystems", Environmental Modelling \& Software, 95,p.p 358-364

2. S. Bartolini, A. Cappello, J. Martí, C. Del Negro(2013). " QVAST: a new Quantum GIS plugin for estimating volcanic susceptibility", Natural Hazards and Earth System Sciences, 13, pp.3031-3042

3. Shashi Shekhar, Hui Xiong(2007). "Encyclopedia of GIS”,SpringerScience and Business Media, ISBN :978-0-387-35973-1.

4. Guido van Rossum,Fred L. Drake, Jr.(2012). "The Python Language Reference”, Python Software Foundation, ISBN 978-1-78216-748-8.

5. Joel Lawhead(2017). “QGIS Python Programming CookBook”,Packt Publishing, ISBN 978-1-78712-483-7

6. Robert E. Carlson(1977). "A trophic state index for lakes”, Limnology and Oceanography, 22(2), 361-369 (1977)

7. Jerry C. Ritchie, Paul V. Zimba, and James H. Everitt, ( 2003 ) "Remote Sensing Techniques to Assess Water Quality", Photogrammetric Engineering And Remote Sensing, 695-704.

8. Jesu' s Ernesto Arias-Gonza'lez, Gilberto Acosta-Gonza'lez, Ne'storMembrillo , Joaqui'n Rodrigo Garza-Pe'rez ,Jose' Manuel Castro-Pe'rez,(2012), "Predicting spatially explicit coral reef fish abundance,richness and Shannon-Weaver index from habitat characteristics", BiodiversConserv: 21:115-130

9. S. R. Carpenter, J. F. Kitchell, J. R. Hodgson, P. A. Cochran, J. J. Elser, M. M.Elser, D. M. Lodge, D. Kretchmer, X. He and C. N. von Ende. (1987), "Regulation Of Lake Primary Productivity By Food Web Structure",Ecology, Vol. 68, No. 6, pp. 1863-1876.

10. Stanley I. Dodson, Shelley E. Arnott, and Kathryn L. Cottingham. (2000). "The Relationship In Lake Communities Between Primary Productivity And Species Richness", Ecology, 81(10), pp. 2662-2679.

11. D. D. French. (1994). "Hierarchical Richness Index (HRI): A SimpleprocedureFor Scoring 'Richness', For Use With Grouped Data, Biological Conservation 69, 207-212.

12. Charles R. Goldman. (1960). "Primary Productivity And Limiting Factors In Three Lakes Of The Alaska Peninsula", Ecological Monographs, Vol. 30, No. 2, pp. 207-230.

13. Charles R. Goldman. (1988), "Primary productivity, nutrients, and transparency during the early onset of eutrophication in ultraoligotrophic Lake Tahoe, California-Nevadal, Limnol. Oceanogr., 33(6, part 1), 1321-1333.

14. C. Heip. (1974), “A New Index Measuring Evenness, J. Mar. biol. Ass. U.K. (1974) 54, 555-557.

15. Prabhata K. Swamee and Aditya Tyagi, P.E., M.ASCE. (2007), "Improved Method for Aggregation of Water Quality Subindices", Journal of Environmental Engineering, 133:220-225.

16. D. Lu, G. Li, G. S. Valladares , M. Batistella. (2004), "Mapping Soil Erosion Risk In Rondo` Nia, Brazilian Amazonia:UsingRusle, Remote Sensing And GIS, Land Degrad. Develop. 15: 499-512.

17. D. Padmalal , K.P.N. Kumaran , K.M. Nair , B. Baijulal , Ruta B. Limaye , S. Vishnu Mohan. (2011), "Evolution of the coastal wetland systems of SW India during the Holocene: Evidence from marine and terrestrial archives of Kollam coast, Kerala”, Quaternary International $237,123-139$.

18. Bruce J. Peterson. (1980), "Aquatic Primary Productivity And The 14C-C02 Method: A History Of The Productivity Problem, Ann. Rev. ECoLSYSL . 11:359-85

19. RachnaBhateria, Disha Jain. (2016), "Water quality assessment of lake water: a review", Sustain. Water Resour. Manag. 2:161-173

20. Fu-Liu Xua,, Zhen-Yan Zhaoa, Wei Zhana, Shan-Shan Zhaoa, R.W. Dawsona,, Shu Tao.(2005), "An ecosystem health index methodology (EHIM) for lake ecosystem health assessment", Ecological Modelling 188, 327-339.

\section{AUTHORS PROFILE}

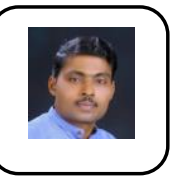

Shibu K, obtained his B.Tech degree in Civil Engineering from University of Kerala, India and thereafter obtained his M.Tech degree in Civil Engineering (Environmental Engineering) from IIT Madras, India. Currently, he is working as Associate
Professor and Head of Environmental Engineering Division at the Department of Civil Engineering, College of Engineering Trivandrum, Thiruvananthapuram-695 016, India. His specialisations include Environmental Impact Assessment, Environmental Management, Sustainable Development, Solid Waste Management, Water Treatment, Air Quality Management and Wastewater Treatment.

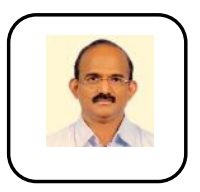

Dr. S. Ayoob, received his B.Tech. degree from University of Kerala, India and thereafter his M.Tech. and Ph.D. degree from IIT Kharagpur India. He is currently the Pro-Vice Chancellor of APJ Abdul Kalam Technological University, Thiruvananthapuram - 695 016 Kerala,India. His research interests are in Wastewater Management, Environmental Chemistry, Water supply systems, Solid waste Management, Industrial water pollution control, Environmental Impact Assessment, Sanitary Microbiology, Water Resources Planning and Environmental hydraulics.
Published By:

Blue Eyes Intelligence Engineering and Sciences Publication (C) Copyright: All rights reserved.

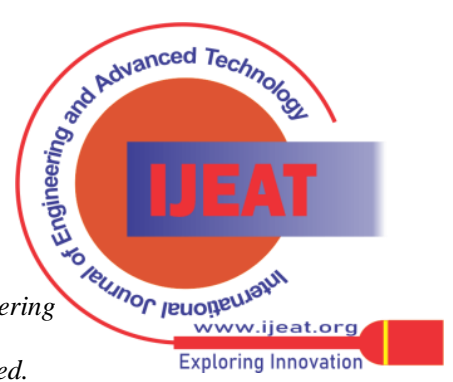

